\title{
Decision Support System for the Assessment of Risk Factors for Type 2 Diabetes and Minimizing the Risk for Complications
}

\author{
Soumaya Fellaji \\ Laboratory of Mathematics and \\ Applications \\ Faculty of Sciences and \\ Technologies (FST), Tangier,
}

Morocco

\author{
Abdellah Azmani \\ Laboratory of Computer Science, \\ Systems and Telecommunications \\ Faculty of Sciences and \\ Technologies (FST), Tangier,
}

Morocco

\author{
Abdelhadi Akharif \\ Laboratory of Mathematics and \\ Applications \\ Faculty of Sciences and \\ Technologies (FST), Tangier,
}

Morocco

\begin{abstract}
Type 2 diabetes is an epidemic disease that knows an exponential increase all over the world. Its micro and macro vascular complications are multiple and they are responsible for many deaths worldwide. To cope with this problem, and exploiting the success of artificial intelligence methods in the field of prevention and decision making in various areas, it becomes essential to think about modeling a decision support system to improve the quality of life of patients with type 2 diabetes and to reduce the risk of its complications. The proposed model provides results showing the usefulness and ability of this artificial intelligence technique for decision making in order to improve the quality of life of patients with type 2 diabetes and to reduce the risk of its complications.
\end{abstract}

\section{General Terms}

Decision Making, Type 2 Diabetes, Lifestyle, Complications.

\section{Keywords}

Health quality, type 2 diabetes, Bayesian Networks, Decision Support System, Complications of Type 2 Diabetes.

\section{INTRODUCTION}

Given the rate of population with type 2 diabetes, the percentage of deaths all over the world by this epidemic and its serious complications, type 2 diabetes is a major health problem that increases exponentially and may reach 15 million African in 2025 according to estimation by the International Diabetes Federation.

Several factors contribute to the risk of becoming diabetic. They are mainly related to urbanization, sedentary lifestyle and changing diets, and eating habits that are high in carbohydrates and fat and generate an obese population. These factors related to lifestyle are the main cause developing type 2 diabetes and its serious complications which can affect the eyes, kidneys, heart, feet, nervous system, etc. In addition, other factors are the cause of this disease, such as advanced age, and genetic predisposition for diabetes.

As part of continuous and real-time monitoring diabetes, and in order to satisfy a safely life and reduce the risk of complications of this disease, this decision support system consist to exploit one of artificial intelligence techniques namely Bayesian Networks which are a powerful tool for the diagnosis and the prevention especially in the medical field. Thus, this system is designed to help diabetics to diagnose their health state and identify risk factors which influence more on the evolution of this disease. It therefore presents recommendations, firstly, to reduce the risk of developing the type 2 diabetes and its complications, and secondly, to promote health and quality of life of people suffering from this disease.

\section{TYPE 2 DIABETES}

\subsection{Definition}

Type 2 diabetes is characterized by elevated glucose level in the blood due to a disorder of glucose metabolism. This elevation, called hyperglycemia occurs when the amount of "insulin", the hormone secreted by the pancreas, is insufficient compared to needs. Therefore, glucose is poorly utilized by cells and generates a hyperglycemia that exceeds the limit of the normal values. It is said that there is insulin resistance. Thus, blood glucose should not exceed $1.10 \mathrm{~g} / \mathrm{l}$. Person has diabetes when his fasting blood glucose is greater than $1.26 \mathrm{~g} / 1$ twice.

The symptoms of this epidemic appear only after a long silence from 8 to 10 years. These symptoms are mentioned: excessive fatigue, increased urine volume, increased thirst, increased hunger, weight loss, blurred vision, and poor wound healing.

Because these symptoms are less pronounced, the diagnosis of type 2 diabetes is often done several years after its appearance when one or more complications are already present in the patient.

\subsection{Risk Factors of Type 2 Diabetes}

Type 2 diabetes is due to some behavioral and genetic risk factors such as sedentary behaviors, obesity, advanced age, poor diet, stress, etc. These risk factors result in significant metabolic and / or physiological changes cited by the World Health Organization (WHO) statistics report [1] as follows:

- Elevation of blood pressure: This metabolic change presents a percentage of $13 \%$ of deaths worldwide. It is the cause of, respectively, $51 \%$ and $45 \%$ of deaths from cerebrovascular accident and coronary heart disease;

- Weight gain progressing to obesity: Overweight or obesity is increasing rapidly. The global prevalence of obesity has reached approximately double between 1980 and 2008 . Women present the highest value of the obese population in the world. Indeed, excess weight is the major factor of several complications such as hypertension, high cholesterol or triglycerides, and may subsequently be a cause of diabetes, coronary heart disease and some 
common cancers. It is because of this excess that each year 2.8 million people die around the world (5\% of deaths). This excess weight is due to a lack of physical activity and poor diet with high calorie [2].

- Hyperglycemia: Clearly, the elevation of fasting glucose is the main risk factor for diabetes disease. However, this increase also increases the risk of cardiovascular death. It presents the cause of, respectively, $22 \%$ and $16 \%$ of deaths from coronary heart disease and cerebrovascular accident. $6 \%$ of deaths are a direct cause of hyperglycemia worldwide.

- Hyperlipidemia: It is defined as the increase of lipids in the blood. It does not provoke symptoms but rather causes complications that are summarized in general in ischemic cerebrovascular accident, arteritis of the lower limbs or in the worst case by arthralgia or abdominal pain or even the occurrence of acute pancreatitis in cases of hypertriglyceridemia.

On the one hand, type 2 diabetes is developed in parallel with obesity that is caused by the decrease in physical activity and diet tending towards fast foods and high calorie foods. To this end, type 2 diabetes has become known even in children than in adolescents. For this, to predict the onset of this disease and prevent its sneaky evolution, it is important to recognize it in the young population with overweight or obesity [2].

On the other hand, with the lifestyle change and the trend towards modernization and urbanization, sedentary behavior has become a major risk factor causing obesity and type 2 diabetes. This risk becomes greater if there is a lack of physical activities. According to the WHO, sedentary behavior is the fourth risk factor for mortality in the world. Its prevalence is increasing very high [3]. Unfortunately, the majority of the world population (about 70\%) neglects the practice of physical activity to protect health and prevent complications of inactivity such as diabetes (27\%), ischemic heart disease $(30 \%)$, the breast cancer $(21 \%)$ and colon cancer $(25 \%)$.

\subsection{Type 2 Diabetes Complications}

Type 2 diabetes causes micro and macro vascular complications. It is responsible for various diseases affecting the eyes, kidneys, heart, blood vessels and nerves and it is the leading cause of mortality in these complications.

A study by Graillot et al. [4] showed that with age and in presence of diabetes, high blood pressure is a risk factor for renal disease and stroke. This factor may also develop cardiovascular disease in the presence of dyslipidemia and smoking if diabetes appeared from eight to ten years. By against, if the age of the onset of diabetes is recent, glycemic control is sufficient to prevent cardiovascular disease. In the same context, Ali [5] showed the relationship between diabetes and hypertension to develop diabetic neuropathy.

\subsection{Treatment of Type 2 Diabetes by Lifestyle Modification}

Type 2 diabetes is a result of an excess of glucose in the blood. This excess is due to a lack of physical activity and overweight due to a sedentary lifestyle and a diet rich in carbohydrates and saturated fats. So, in order to control blood sugar levels in the blood, the prescription of exercise is a major factor in fighting against diabetes by improving blood sugar control. This prescription contributes to the lifestyle change for the treatment of type 2 diabetes and therefore corrects the sedentary behavior. It helps also in improving the quality of health and treatment of type 2 diabetics [4],[6]. In addition, diet plays an important role in the balance of carbohydrate intake and protein. It is an important element for the prevention of kidney disease. Surveys have shown the capacity and tendency of type 2 diabetics to follow a diet and make efforts to control their blood glucose [7].

Mayer-Davis and Costacou [8] explained the risk of type 2 diabetes in the case of obesity and the role of weight loss and exercise to minimize the risk of type 2 diabetes. Furthermore, in combination with physical activity, a diet with reduced amounts of fat and calories and rich in fiber helps in weight loss and improving insulin concentrations and glucose.

Similarly, a study about the impact of physical activity among type 2 diabetics showed the role of this factor in improving glycemic control and prevention of type 2 diabetes regardless their diet. It is also able to reduce the risk of complications of this disease [9].

Furthermore, other studies have shown that time spent watching television increases the risk of obesity both for children and adults. Thus, sedentary behaviors should be reduced in order to prevent type 2 diabetes [10].

\section{BAYESIAN MODEL}

\subsection{Definition}

Bayesian networks are probabilistic graphical models that allow representing, acquiring, and exploiting knowledge. They represent random variables in the form of a directed acyclic graph. The relationships between these variables are relations of cause and effect and are not deterministic but probabilistic. Bayesian networks are used mainly in issues of risk analysis, detection and data mining diagnosis. They also allow to take into account a priori knowledge of experts [11], [12].

A Bayesian Network $B=(G, \theta)$ is defined by:

- The set of observable random variables :

$$
\mathrm{X}=\{\mathrm{X} 1, \ldots \ldots, \mathrm{Xn}\} .
$$

- $\mathrm{G}=(\mathrm{X}, \mathrm{E})$, directed acyclic graph (DAG), where each node is associated to a variable $X$.

- $\theta=\{\theta \mathrm{i}\}=\mathrm{P}(\mathrm{Xi} \mid \mathrm{Pa}(\mathrm{Xi}))\}$, set of probability distributions for each node Xi conditionally on its immediate parents in the graph $\mathrm{G}$.

$$
\mathrm{P}(\mathrm{X} 1, \mathrm{X} 2, \ldots, \mathrm{Xn})=\prod_{\mathrm{i}=\mathbb{1}}^{\mathrm{n}} \mathrm{P}(\mathrm{Xi} \mid \mathrm{Pa}(\mathrm{Xi}))
$$

\subsection{Bayes Theorem}

Given two events $\mathrm{E}$ and $\mathrm{F}$ such that $\mathrm{P}(\mathrm{E}) \neq 0$ and $\mathrm{P}(\mathrm{F}) \neq 0$, we have:

$$
P(E \mid F)=\frac{P(F \mid E) P(E)}{P(F)}
$$

In addition, given the $\mathrm{n}$ mutually exclusive and exhaustive events E1, E2, E3, ..., En, such that for all $\mathrm{i}: \mathrm{P}(\mathrm{Ei}) \neq 0$ with $1 \leq \mathrm{i} \leq \mathrm{n}$, we have :

$$
P(E i \mid F)=\frac{P(F \mid E i) P(E i)}{P(F \mid E 1) P(E 1)+\ldots+P(F \mid E n) P(E n)}
$$

\subsection{Applications of Bayesian Networks}

Bayesian networks can be used in various applications depending on the goal. They allow predicting, diagnosing, simulating, monitoring, analyzing system data and making decisions. The areas of applications are as diverse as the 
context of the use of this technique. It can be applied in the medical field, industrial, financial, information technology, marketing, etc. [12]. Several projects have been implemented by exploiting this technique. I. Maglogiannis and al. [13] used the Bayesian network into a platform for risk analysis applied to a monitoring system of vital signs for telemedicine home care. At the same axis, M. Athanasiou and J. Y. Clark [14] have exploited this technique in the process of care for monitoring wheelchair users with spinal cord injury. Other studies have harnessed the power of Bayesian networks in various fields such as the prediction of electricity consumption [15], the study of the context and multi-target tracking [16], modeling and learning complex systems [17], the study of population genetics [18], daily mobility in over a hundred cities around the world [19] and the vulnerability of a goods warehouse to the risk of fire [20].

\section{PROPOSED MODEL}

\subsection{Aims}

Taking into account the complications caused by type 2 diabetes and its increasing prevalence in the world, it has become essential to think about designing an intelligent system for the permanent and continuous monitoring of people suffering from this epidemic. This system is based on assessment of risk factors and the lifestyle of the person under surveillance in order to meet a quality of life and healthcare of these patients. Thus, to achieve this objective, this proposed model consists of applying the technique of Bayesian Networks that combines the graphical model with probabilistic model. On one hand, this combination offers clear viewing of the problem from the graph. On the other hand, it provides an evaluation of the results obtained from the calculation of a posteriori probabilities based on prior probabilities already assigned to each node of the created model. Thus, the power of Bayesian Network is its ability to make the diagnosis and the prevention of the problem from a single graphical model.

Therefore, this model is based on causes that represent the major risk factors increasing the risk of type 2 diabetes and subsequently accelerates the onset of complications. Its aim is to reduce the risk of complications, anticipate crises and provide personalized recommendations offering better quality management monitoring for type 2 diabetics.

\subsection{Variables Identification}

The proposed model aims to reduce the risk of type 2 diabetes complications (T2DM) by balancing blood sugar levels. This balance cannot be satisfied only from a permanent lifestyle monitoring which reduces the risk of T2DM. Thus, this model is based on T2DM risk factors to assess the change and development of this disease. The main variables influencing its development are (Table 1): poor diet and sedentary behaviors that increase the risk of obesity, genetic predisposition, and physical activity that is an essential factor in improving the quality of treatment T2DM.

Table 1. Variable descriptions of Bayesian Network

\begin{tabular}{|c|l|}
\hline Identifier & \multicolumn{1}{|c|}{ Description } \\
\hline AD & Unbalanced diet \\
\hline S & Sedentary lifestyle \\
\hline O & Obesity \\
\hline AP & Physical activity \\
\hline
\end{tabular}

\begin{tabular}{|c|l|}
\hline FG & Genetic factor \\
\hline D & Diabetes \\
\hline
\end{tabular}

As physical activity plays an important role in preventing and reducing the risk of $\mathrm{T} 2 \mathrm{D}$ regardless of age and other risk factors [21], this model is based on the major risk factors related to the patient lifestyle. In addition, even in the presence of physical activity, sedentary behavior contributes to the development of obesity, the increasing risk of T2D and its complications. Also, a balanced diet is one way to reduce this risk [9]. Whence, the choice of nodes in the proposed model.

\subsection{Priori Probabilities}

To test the validity of this model, the prior probabilities are assigned based on the statistics provided by the World Health Organization and data in the literature showing the effect of risk factors [9]. The allocation of these probabilities does not affect the relevance of the results or the structure of the proposed model. They are used to validate the modeling of the proposed network structure to be able to project it in a real case study, in progress, of type 2 diabetics in Morocco.

Thus, according to the lifestyle of the Moroccan population which is in the process of modernization and trend towards fast food and considering the socio-economic data, the proportion of people who have an unbalanced diet can reach $73 \%$. That of the sedentary population is $65 \% .33 \%$ of the population has a genetic predisposition, while only $13.5 \%$ practice physical activities (sports, walking briskly, etc.).

Table 2. Probabilities description

\begin{tabular}{|l|l|}
\hline \multicolumn{1}{|c|}{ Identifier } & \multicolumn{1}{c|}{ Description } \\
\hline $\mathrm{P}(\mathrm{AD})$ & $\begin{array}{l}\text { Probability of people with an unbalanced } \\
\text { diet. }\end{array}$ \\
\hline $\mathrm{P}(\mathrm{S})$ & Probability of sedentary people. \\
\hline $\mathrm{P}(\mathrm{FG})$ & $\begin{array}{l}\text { Probability of people who have a genetic } \\
\text { predisposition for diabetes. }\end{array}$ \\
\hline $\mathrm{P}(\mathrm{O})$ & Probability of obese people. \\
\hline $\mathrm{P}(\mathrm{O} \mid \mathrm{AD}, \mathrm{S})$ & $\begin{array}{l}\text { Probability of obesity knowing } \\
\text { unbalanced diet and sedentary lifestyle. }\end{array}$ \\
\hline $\mathrm{P}(\mathrm{D} \mid \mathrm{O}, \mathrm{FG}, \mathrm{A})$ & $\begin{array}{l}\text { Probability of diabetes knowing obesity, } \\
\text { genetic predisposition of diabetes and } \\
\text { physical activity. }\end{array}$ \\
\hline
\end{tabular}

\subsection{Graphical Model}

After identifying nodes (variables) that influence on T2DM risk control as well as their prior probabilities, the graph model consists of connecting these nodes according to the causal relationships by giving each node its prior probability. These variables take two values: $\mathrm{T}$ (True) in the presence of a risk factor and $\mathrm{F}$ (False) if this risk factor is absent.

As shown in Fig 1, the major risk factors of T2DM are: the genetic factor, physical activity, and obesity which is caused by sedentary behaviors and poor diet. These two latter factors are also causes of T2DM.

\subsection{Results}

The objective of this paper is to assess the risk of complications from the evaluation of the impact of various risk factors on the variation of risk of type 2 diabetes. To achieve this objective, a posteriori probability calculation was made taking into account every time one or more risk factors 
knowing that the person has type 2 diabetes. These results were obtained using Bayes' theorem (2) and the formula (1) to calculate the overall probability distributions of each node conditional on its immediate parent in the graph.

Table 3. Obtained results according to various risk factors

\begin{tabular}{|l|l|c|}
\hline $\mathbf{N}^{\circ}$ & \multicolumn{1}{|c|}{ Probability } & Value \\
\hline R1 & $\mathrm{P}(\mathrm{D}=\mathrm{V} \mid \mathrm{AP}=\mathrm{V}, \mathrm{AD}=\mathrm{V})$ & 0.168127 \\
\hline R2 & $\mathrm{P}(\mathrm{D}=\mathrm{V} \mid \mathrm{AP}=\mathrm{V}, \mathrm{AD}=\mathrm{F})$ & 0.125367 \\
\hline R3 & $\mathrm{P}(\mathrm{D}=\mathrm{V} \mid \mathrm{AP}=\mathrm{V})$ & 0.156582 \\
\hline R4 & $\mathrm{P}(\mathrm{D}=\mathrm{V} \mid \mathrm{AP}=\mathrm{V}, \mathrm{S}=\mathrm{V})$ & 0.164065 \\
\hline R5 & $\mathrm{P}(\mathrm{D}=\mathrm{V} \mid \mathrm{AP}=\mathrm{V}, \mathrm{FG}=\mathrm{V})$ & 0.243320 \\
\hline R6 & $\mathrm{P}(\mathrm{D}=\mathrm{V} \mid \mathrm{AP}=\mathrm{F}, \mathrm{FG}=\mathrm{V})$ & 0.486640 \\
\hline R7 & $\mathrm{P}(\mathrm{D}=\mathrm{V} \mid \mathrm{AP}=\mathrm{V}, \mathrm{O}=\mathrm{V})$ & 0.186300 \\
\hline R8 & $\mathrm{P}(\mathrm{D}=\mathrm{V} \mid \mathrm{AP}=\mathrm{V}, \mathrm{O}=\mathrm{F})$ & 0.079400 \\
\hline R9 & $\mathrm{P}(\mathrm{D}=\mathrm{V} \mid \mathrm{AP}=\mathrm{V}, \mathrm{AD}=\mathrm{V}, \mathrm{O}=\mathrm{V})$ & 0.186300 \\
\hline R10 & $\mathrm{P}(\mathrm{D}=\mathrm{V} \mid \mathrm{AP}=\mathrm{F}, \mathrm{AD}=\mathrm{V}, \mathrm{O}=\mathrm{V})$ & 0.372600 \\
\hline R11 & $\mathrm{P}(\mathrm{D}=\mathrm{V} \mid \mathrm{S}=\mathrm{V}, \mathrm{AD}=\mathrm{V})$ & 0.327513 \\
\hline R12 & $\mathrm{P}(\mathrm{D}=\mathrm{V} \mid \mathrm{S}=\mathrm{F}, \mathrm{AD}=\mathrm{V})$ & 0.287639 \\
\hline R13 & $\mathrm{P}(\mathrm{D}=\mathrm{V} \mid \mathrm{S}=\mathrm{F})$ & 0.266107 \\
\hline R14 & $\mathrm{P}(\mathrm{D}=\mathrm{V} \mid \mathrm{S}=\mathrm{V})$ & 0.461625 \\
\hline R15 & $\mathrm{P}(\mathrm{D}=\mathrm{V} \mid \mathrm{S}=\mathrm{V}, \mathrm{FG}=\mathrm{V})$ & 0.461625 \\
\hline R16 & $\mathrm{P}(\mathrm{D}=\mathrm{V} \mid \mathrm{S}=\mathrm{V}, \mathrm{FG}=\mathrm{F})$ & 0.229320 \\
\hline R17 & $\mathrm{P}(\mathrm{D}=\mathrm{V} \mid \mathrm{O}=\mathrm{V}, \mathrm{FG}=\mathrm{V})$ & 0.484900 \\
\hline
\end{tabular}

\begin{tabular}{|l|l|l|}
\hline R18 & $\mathrm{P}(\mathrm{D}=\mathrm{V} \mid \mathrm{O}=\mathrm{V}, \mathrm{FG}=\mathrm{F})$ & 0.279750 \\
\hline R19 & $\mathrm{P}(\mathrm{D}=\mathrm{V} \mid \mathrm{AD}=\mathrm{F})$ & 0.233809 \\
\hline
\end{tabular}

\subsection{Discussion}

The analysis of these results shows clearly the role of physical activity in improving glycemic control. In the case of R4 results, R5 and R7, there is a decrease in risk of type 2 diabetes regardless of the diet despite the presence of a risk factor in all three cases which are successively: sedentary lifestyle, genetic predisposition and obesity. Whereas in the absence of physical activity, and in the presence of risk factors, the values obtained are maximum in the case of R6 results, R15 and R17. If the diabetic practice a physical activity (R3) or following a balanced diet (R19), risk values are reduced whatever the risk factors. This result shows that the recommendations for diabetics must be customized and adapted to the patient's health status. In other words, for people who have health problems that prevent them to be physically active, it is strongly recommended to follow a diet rich in fiber to absorb the excess of glucose in the blood. While for those who are able to follow physical activities such as walking briskly for a minimum of 30 minutes a day, they can improve their health quality by following these activities. Improving the quality will be better if these people also follow a diet rich in fiber and balanced in carbohydrates and fats (R2). In addition, when the patient keeps his normal weight and follows physical activities, risk value is optimal (R8). In conclusion, the modeling of this problem using Bayesian Networks is consistent with results obtained in [9] that showed the important role of physical activity for blood sugar control.

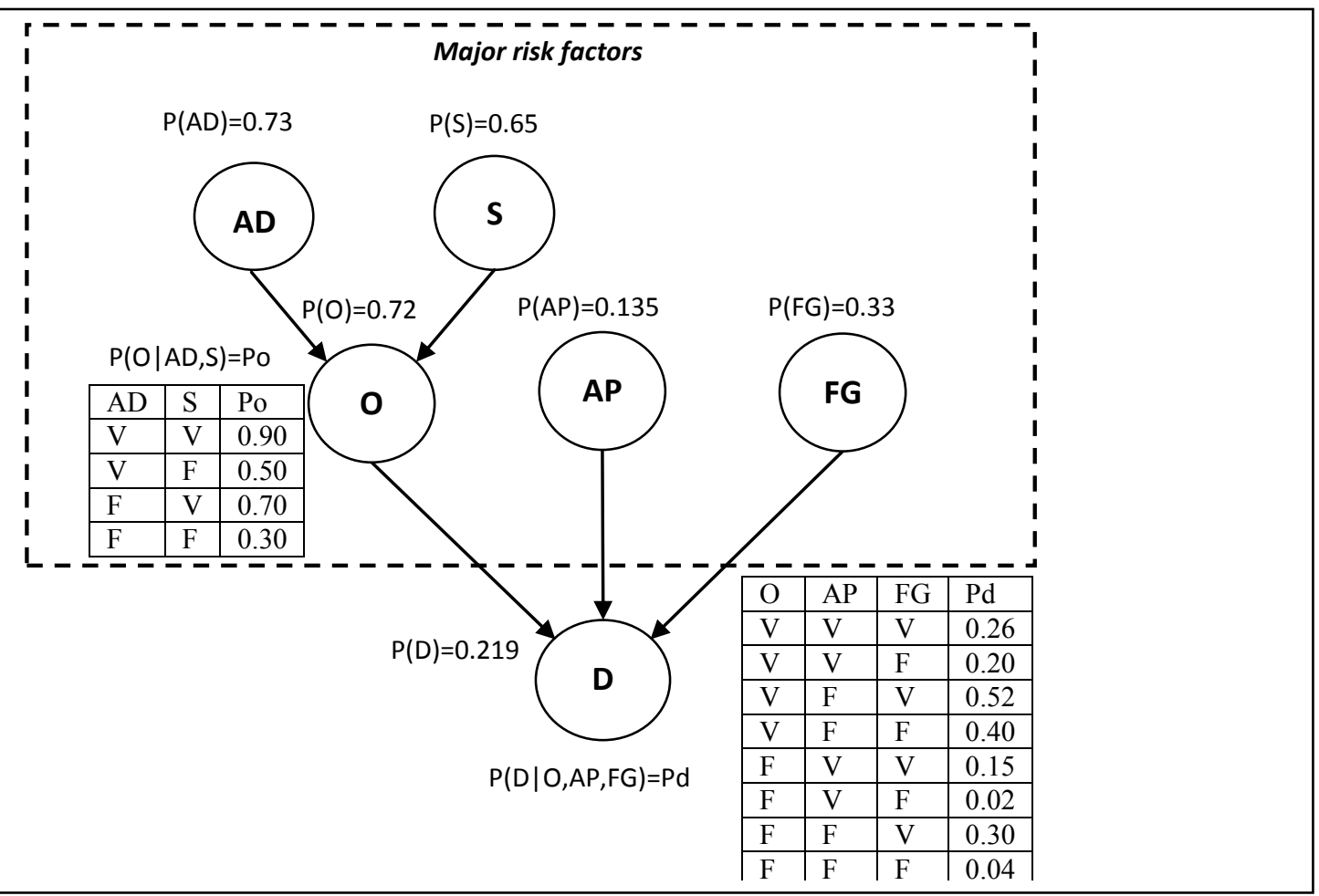

Fig 1: Bayesian model of proposed system 


\section{CONCLUSION AND PERSPECTIVES}

This paper presented a model for improving the quality of life of type 2 diabetic glycemic control and prevention of risk of complications from an evaluation of type 2 diabetes risk factors. This modeling showed the role of the artificial intelligence technique for decision making and improving the quality of care for type 2 diabetics. In addition, the results showed the possibility of applying Bayesian Networks in this discipline. It is a preliminary step for the implementation of the decision support system for monitoring type 2 diabetics whose architecture is presented in the article [22]. Thus, this system will help to assess risk factors and provide recommendations according to the health state of monitored person and therefore to optimize the risk of complications of type 2 diabetes. The prospects of this work are intended to improve the model taking into account other risk factors in order to lead to more optimized values and to offer recommendations depending on the patient's vital signs. A socio-economic study is under way to implement the actual data in the proposed model.

\section{ACKNOWLEDGMENTS}

We thank Dr. Abdellatif Benslimane, the president of the "Association Averroes of Diabetes". He helps us to verify the cause/effect relationships between the nodes of the proposed model. He helps us also to make inquiries with diabetics who follow their health status in the association. Our thanks are as well intended to members who helped us succeed in our surveys especially Mrs Samira Bakkali the director of the association.

\section{REFERENCES}

[1] Statistiques sanitaires mondiales 2012. Genève: Organisation Mondiale de la Santé, 2012.

[2] T. Mouraux and H. Dorchy, "Le poids de l'obésité dans le (pré) diabète de type 2 chez les enfants et adolescents: quand et comment le rechercher?," Arch. Pédiatrie, vol. 12 , no. 12, pp. 1779-1784, 2005.

[3] W. H. Organization, "Stratégie mondiale de l'OMS pour l'alimentation, l'exercice physique et la santé: cadre de suivi et d'évaluation de la mise en oeuvre," 2009.

[4] D. Graillot, V. Quipourt, B. Bouillet, J.-M. Petit, and P. Manckoundia, "Diabète de type 2 chez le sujet âgé: quelles spécificités?," Rev. Médecine Interne, vol. 33, no. 10, pp. 575-579, Oct. 2012.

[5] R. A. Ali, "Management of diabetic neuropathy," Malays. J. Med. Sci. MJMS, vol. 10, no. 2, p. 27, 2003.

[6] J.-F. Brun, S. Bordenave, E. Ghanassia, M.-C. Picot, A. Jaussent, J. Mercier, and C. Prefaut, "Le réentraînement à l'activité physique dans le diabète de type 2 réduit les dépenses de santé : résultats d'une étude prospective," Sci. Sports, vol. 23, no. 3-4, pp. 193-197, Jun. 2008.

[7] H. Gin, "Nutrition et diabète: diététique pratique," EMCMédecine, vol. 1, no. 1, pp. 46-50, 2004.

[8] E. J. Mayer-Davis and T. Costacou, "Obesity and sedentary lifestyle: modifiable risk factors for prevention of type 2 diabetes," Curr. Diab. Rep., vol. 1, no. 2, pp. 170-176, 2001.

[9] M. Duclos, J.-M. Oppert, B. Vergès, V. Coliche, J.-F. Gautier, C.-Y. Guezennec, G. Reach, and G. Strauch, "Activité physique et diabète de type 2: Référentiel de la Société francophone du diabète (SFD), 2011," Médecine Mal. Métaboliques, vol. 6, no. 1, pp. 80-96, 2012.

[10] F. B. Hu, "Sedentary lifestyle and risk of obesity and type 2 diabetes," Lipids, vol. 38, no. 2, pp. 103-108, 2003.

[11] R. E. Neapolitan, Learning bayesian networks. Pearson Prentice Hall Upper Saddle River, 2004.

[12] P. Naïm, P.-H. Wuillemin, P. Leray, O. Pourret, and A. Becker, Réseaux bayésiens. Eyrolles, 2011.

[13] I. Maglogiannis, E. Zafiropoulos, A. Platis, and C. Lambrinoudakis, "Risk analysis of a patient monitoring system using Bayesian Network modeling," J. Biomed. Inform., vol. 39, no. 6, pp. 637-647, Dec. 2006.

[14] M. Athanasiou and J. Y. Clark, "A Bayesian network model for the diagnosis of the caring procedure for wheelchair users with spinal injury," Comput. Methods Programs Biomed., vol. 95, no. 2, pp. S44-S54, Aug. 2009.

[15] T. Launay, "Méthodes bayésiennes pour la prévision de consommation l'électricité," Université de Nantes, 2012.

[16] B. Jida, "Intégration du contexte par réseaux bayésiens pour la détection et le suivi multi-cibles," 2008.

[17] P. Leray, "Réseaux Bayésiens: apprentissage et modélisation de systèmes complexes," Habilit. À Dir. Rech. Univ. Rouen, 2006.

[18] M. Blum, "Statistique bayésienne et applications en génétique des populations," Université de Grenoble, 2012.

[19] G. Fusco, "La mobilité quotidienne dans les grandes villes du monde: application de la théorie des réseaux bayésiens," Cybergeo Eur. J. Geogr., 2004.

[20] H. Bakkali, S. K. Issa, and A. Azmani, "The modeling of fire hazards in a goods warehouse by the Bayesian network," Int. J. Emerg. Trends Eng. Dev., pp. 22496149, 2013.

[21] M. Duclos, J.-M. Oppert, B. Verges, V. Coliche, J.-F. Gautier, Y. Guezennec, G. Reach, and G. Strauch, "Physical activity and type 2 diabetes. Recommandations of the SFD (Francophone Diabetes Society) diabetes and physical activity working group," Diabetes Metab., vol. 39, no. 3, pp. 205-216, May 2013.

[22] S. Fellaji, A. Azmani, and A. Akharif, "Conception of Decision Support Tool for the Prevention and Detection of Type 2 Diabetes.," Int. J. Comput. Appl., vol. 76, 2013. 